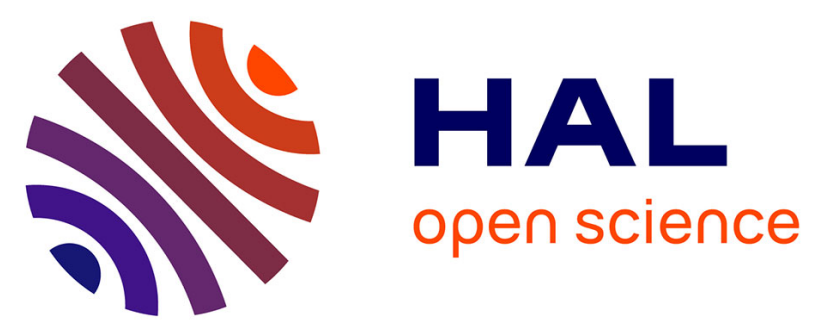

\title{
Subacute static magnetic field exposure in rat induces a pseudoanemia status with increase in MCT4 and Glut4 proteins in glycolytic muscle
}

\author{
Miryam Elferchichi, Jacques Mercier, Mohamed Ammari, Hatem Belguith, \\ Hafedh Abdelmelek, Mohsen Sakly, Karen Lambert
}

\section{To cite this version:}

Miryam Elferchichi, Jacques Mercier, Mohamed Ammari, Hatem Belguith, Hafedh Abdelmelek, et al.. Subacute static magnetic field exposure in rat induces a pseudoanemia status with increase in MCT4 and Glut4 proteins in glycolytic muscle. Environmental Science and Pollution Research, 2016, 23 (2), pp.1265-1273. 10.1007/s11356-015-5336-3 . hal-01817677

\section{HAL Id: hal-01817677 \\ https://hal.umontpellier.fr/hal-01817677}

Submitted on 4 Dec 2019

HAL is a multi-disciplinary open access archive for the deposit and dissemination of scientific research documents, whether they are published or not. The documents may come from teaching and research institutions in France or abroad, or from public or private research centers.
L'archive ouverte pluridisciplinaire HAL, est destinée au dépôt et à la diffusion de documents scientifiques de niveau recherche, publiés ou non, émanant des établissements d'enseignement et de recherche français ou étrangers, des laboratoires publics ou privés. 


\title{
Subacute static magnetic field exposure in rat induces a pseudoanemia status with increase in MCT4 and Glut4 proteins in glycolytic muscle
}

\author{
Miryam Elferchichi $^{1,2} \cdot$ Jacques Mercier $^{2} \cdot$ Mohamed Ammari $^{1} \cdot$ Hatem Belguith $^{1}$ • \\ Hafedh Abdelmelek $^{1} \cdot$ Mohsen Sakly $^{1}$ - Karen Lambert ${ }^{2}$
}

\begin{abstract}
The purpose of this study was to investigate the effect of subacute exposure to static magnetic fields (SMF) on hematological and muscle biochemical parameters in rats. Male Wistar rats, daily exposed to SMF, were exposed to SMF (128 $\mathrm{mT}, 1 \mathrm{~h}$ /day) during 15 consecutive days. SMF-exposed rats showed a significant decrease in red blood cell (RBC) count, hemoglobin $(\mathrm{Hb})$, and hematocrit $(\mathrm{Ht})$ values compared to sham-exposed rats $(p<0.05)$. Concomitant decreases of plasma iron level against increase in transferrin amount were also observed after SMF exposure $(p<0.0 .05)$. In postprandial condition, SMF-exposed rats presented higher plasma lactate $(p<0.01)$. Additionally, SMF exposure increased monocarboxylate transporters (MCT4) and glucose transporter 4 (Glut4)'s contents only in glycolytic muscle $(p<0.05)$. SMF exposure induced alteration of hematological parameters; importantly, we noticed a pseudoanemia status, which seems to affect tissue oxygen delivery. Additionally, SMF exposure seems to favor the extrusion of lactate from the cell to the blood compartment. Given that, these arguments advocate for an adaptive response to a hypoxia status following SMF exposure.
\end{abstract}

Responsible editor: Philippe Garrigues

Miryam Elferchichi

Miryam.Elferchichi@,ssb.rnu.tn

Laboratoire de Physiologie Intégrée, Faculté des Sciences de Bizerte, Université de Carthage, Jarzouna 7021, Tunisia

PHYMEDEXP, INSERM U1046, CNRS UMR 9214, Université de Montpellier, Montpellier, France
Keywords Static magnetic field · Hematological parameters · MCT transporters · Glut4 $\cdot$ Rat

\section{Introduction}

Despite the omnipresence of static magnetic fields (SMF) in our environment, their potential health effects have received less attention than, for example, extremely low-frequency fields. SMF are naturally present as the Earth's magnetic field (SMF from 25 to $65 \mu \mathrm{T}$ ) (Feychting 2005). Superimposed on the Earth's magnetic field are man-made static magnetic fields such as magnetic resonance imaging (MRI) diagnosis, passenger transport systems that are based on magnetic levitation, industrial processes such as aluminum production, the chloralkali process (SMF from 4 to $50 \mathrm{mT}$ ) (Kowalczuk et al. 1991), and gas welding (World Health Organisation 2006). Although the number of artificial sources of SMF is limited, there are rapid developments of new technologies producing static fields; in parallel, the number of people that can be exposed to SMF is also growing. Therefore, it has become necessary to systematically elucidate their possible influence on the body. SMF affect biological systems through three ways of interactions: magnetic induction, electronic interaction, and magnetomechanical interaction (Binhi 2002; Repacholi and Greenebaum 1999). The latter one including the orientation of magnetically anisotropic structures such as hemoglobin $(\mathrm{Hb})$. Looking at the previous published studies, SMF seemed to affect $\mathrm{Hb}$ structure and function (Ali et al. 2003; Atef et al. 1995; Hassan and Abdelkawi 2010). Thus, exposure to SMF of 0.1-1 T has been reported to influence hemoglobin's conformal stability and the kinetics of the oxyhemoglobin autooxidation reaction (Atef et al. 1995). It was documented that SMF exposure to a range of $0.5-1.5 \mathrm{~T}$ induced different degrees of globin unfolding, which is termed 
as a sign of molecular destabilization with a decrease in oxygen affinity (Hassan and Abdelkawi 2010). Hb picks up the oxygen in the lungs and then releases it in the muscles and other tissues where it is needed. It also contains iron, which is critical for it to work properly. A major consequence of the decrease in supplying oxygen is the appearance of tissue hypoxia; knowing that in hypoxia state, cells are oriented to an anaerobic metabolism, which is marked by an increase in lactate metabolism. Therefore, the question arises what is the impact of possible hematological alterations following SMF exposure on metabolism?

Although the effects of SMF on in vivo metabolism are important to be known, they are so far underestimated. Indeed, proceeding realized by Havas (2008) deals with appearance of a new type of diabetes; following electromagnetic field (EMF) transients therefore, in addition to lifestyle and genetics, the environment appears to be another factor contributing to high levels of blood sugar. However, this study regarded the effects of radio frequency fields and evaluated them only by plasma and blood glucose (Havas 2008). For instance, our previous study (Elferchichi et al. 2010) revealed that SMF-exposed rats displayed significantly higher glycemia and lower insulinemia. Additionally, SMF-exposed rats also presented higher plasma lactate concentrations and an increase in lactate dehydrogenase activity against a decrease in citrate synthase activity only in glycolytic muscles that testifies a shift from oxidative to glycolytic metabolism. Skeletal muscle is the major producer of lactate in the body and the rate of production increase in many physiological (i.e., exercise and altitude) and physiopathological situations (i.e., obesity, insulinoresistance, and hypoxia) (Py et al. 2001). In either case, lactate is an important metabolic intermediate, which can exchange rapidly between different cells. These processes require lactic acid transport across the sarcolemma and involve a proton-linked monocarboxylate transporter (MCT). Skeletal muscle contains both MCT1 (Michaelis constant $\left(K_{\mathrm{m}}\right)$ of $5 \mathrm{mM}$ ) and MCT4 (Michaelis constant $\left(K_{\mathrm{m}}\right)$ of $20 \mathrm{mM}$ ) transporters. The latter is found in all fiber types, although least in more oxidative red muscles such as soleus (SOL), whereas expression of MCT1 is highest in the more oxidative muscles and very low in white muscles that are almost entirely glycolytic (Juel and Halestrap 1999).

Knowing that, $128 \mathrm{mT} \mathrm{SMF}$ is in the range of the intensity reached in the vicinity of MRI equipment (Saunders 2005) and is close to the $0.2 \mathrm{~T}$ (time-weighted-average exposure for whole body) limit for an 8-h working day proposed by the National Radiological Protection Board in the UK (McRobbie 2012; Schenck 2000). In the present study and on the basis of our previous data, we attempt initially to evaluate the impact of $128 \mathrm{mT}$ SMF exposure on hematological and biochemical parameters and secondly to make preliminary results about the involvement of lactate and glucose transporters in the metabolic alterations.

\section{Materials and methods}

\section{Animals and protocol}

Animal care and experimental procedures were carried out in accordance with the Tunisian Code of Practice for the Care and Use of Animals for Scientific Purposes, and the experimental protocol was approved by the Faculty Ethics Committee (Faculté des Sciences de Bizerte, Tunisia).

Twelve 6-7-week-old male Wistar rats were housed $(n=3$ / cage) in a temperature-controlled room at $25^{\circ} \mathrm{C}$ with a relative humidity of $80 \%$ and a 12:12-h light-dark cycle (light on at $8 \mathrm{AM})$. Water and food were available ad libitum. Rats were randomly divided into two groups: rats exposed to $128 \mathrm{mT}$ SMF ( $n=6, \mathrm{SMF})$ and sham-exposed rats $(n=6$, sham exposed). Rats exposed to $128 \mathrm{mT} \mathrm{SMF}$ and sham-exposed rats were placed in the electromagnet between 8 and $12 \mathrm{AM}$ under standard light exposure for $1 \mathrm{~h}$ /day during 15 consecutive days. To avoid effects due to circadian rhythms and other uncontrolled factors, sham and exposed animals were placed in the electromagnet alternatively. For the first week, shamexposed rats were placed in the electromagnet between 8 and $10 \mathrm{AM}$ and SMF-exposed rats between 10 and $12 \mathrm{AM}$. For the second week, we inverted the period of exposure, i.e., sham-exposed between 10 and $12 \mathrm{AM}$ and SMF-exposure between 8 and $10 \mathrm{AM}$.

All rats were sacrificed between 9 and 12 AM thus in postprandial state due to their feeding schedule, i.e., feeding during dark phase.

\section{Exposure system}

We used an electromagnet (Model EM4-HVA, Lake Shore Cryotronics, Inc., Westerville, OH, USA; Fig. 1) and a magnet power supply (Model 647, Lake Shore Cryotronics, Inc.) with an air gap of $11 \mathrm{~cm}$. This apparatus incorporates water-cooled coils and precision yokes that assure precise cap alignment and excellent field stability and uniformity when high power is required to achieve the maximum field capability for the electromagnet. SMF intensity was measured and standardized over the total floor area of the Plexiglass cage at $128 \mathrm{mT}$. SMF uniformity in the active exposure volume was $\pm 0.2 \%$ over $1 \mathrm{~cm}^{3}$. The cage measured $20 \times 10 \times 20 \mathrm{~cm}$. The two coils of the Lake Shore electromagnet were separated by a $12.1-\mathrm{cm}$ gap. Exposed and sham-exposed rats ( $n=2 /$ each time) were placed in the cage at the center of the uniform field area and exposed, or not, to $128 \mathrm{mT} \mathrm{SMF}$. 
Fig. 1 Lake Shore Electromagnets (Lake Shore Cryotronics, Inc., Westerville, $\mathrm{OH}$, USA) (Abdelmelek et al. 2006)

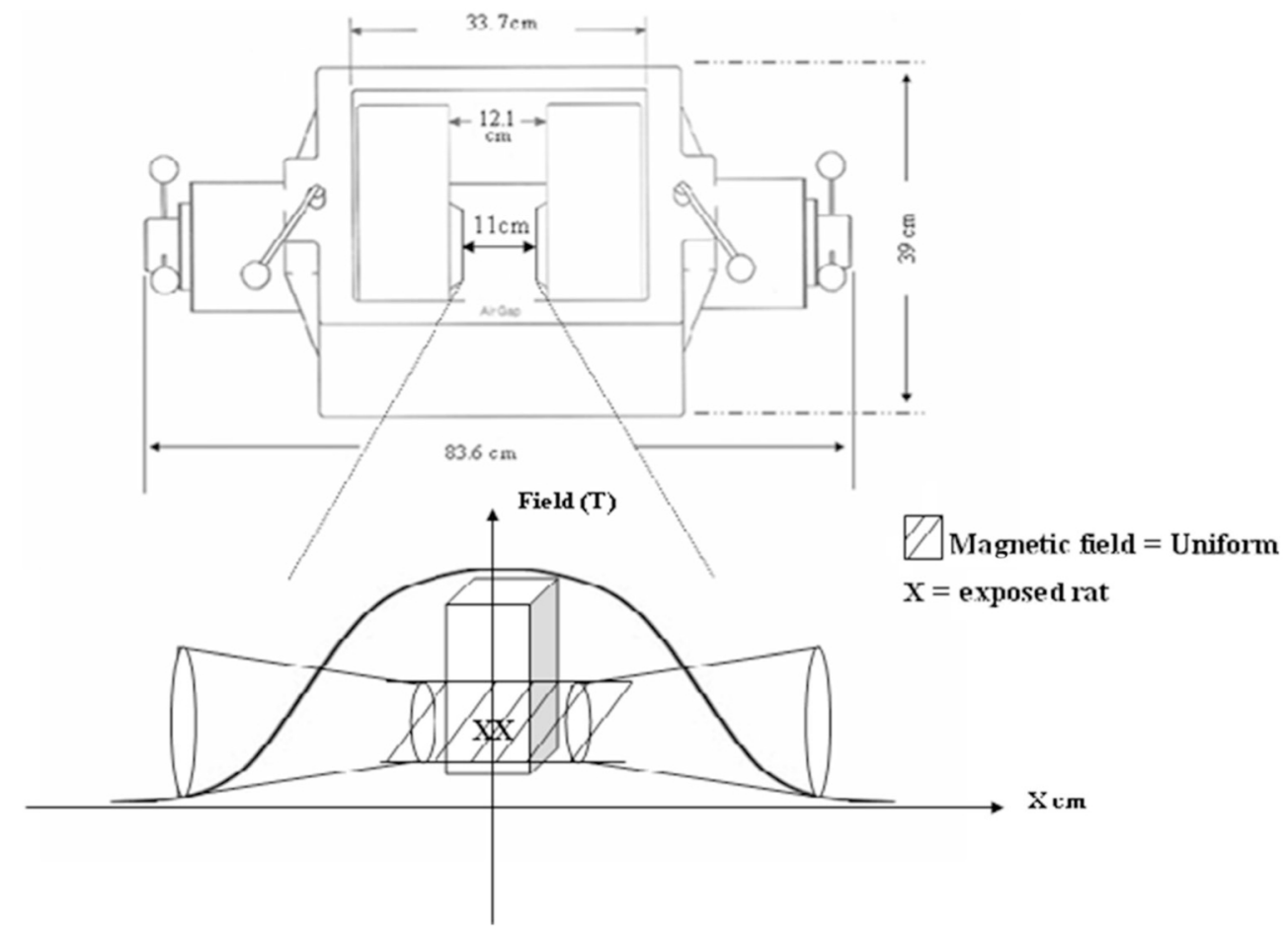

\section{Blood chemistry}

Exposed and sham-exposed rats were sacrificed by decapitation in postprandial state. Blood samples $(0.5 \mathrm{~mL} / \mathrm{sample})$ were collected in vials (Hematology Department, Regional Hospital Bizerte, Tunisia), containing ethylenediaminetetraacetic acid (EDTA) (Sigma, Tunis, Tunisia) for hematological investigations. Hematological parameters were assayed by precision instruments for hematology research (Medonic CA 620, Paris, France).

Blood samples were centrifuged and plasma aliquots were frozen and stored at $-80{ }^{\circ} \mathrm{C}$ until use. Plasma iron was measured by using colorimetric method according to manufacturer's instructions (Biomaghreb, Réf. 20061, Tunis, Tunisia). Plasma transferrin was measured by using quantitative analysis of immunochemical reaction tanks to use Behring Nephelometer II analyzer (Biomaghreb, Tunis, Tunisia), which offer an entirely automatic quantitative determination of proteins by means of nephelometry.

Plasma glucose and insulin concentrations were determined from standard curves generated at the same time using enzymatic methods and radioimmunoassay following the manufacturer's instructions (Sigma 510 and SRI-13K, Labodia, Montpellier, France). Lactate concentration was determined according to the method of Gutmann and Wahlefeld (1974).

\section{Tissue sampling}

Immediately after sacrifice, the soleus (SOL; oxidative muscle) and the extensor digitorum longus (EDL; glycolytic muscle) of the hind limb were removed, frozen in liquid nitrogen, and stored at $-80{ }^{\circ} \mathrm{C}$ until use for Western blotting of MCT1, MCT4, and glucose transporter 4 (Glut4).

\section{Sample preparation for Western blotting}

Proteins were isolated from muscles for Western blotting, as previously described by McCullagh et al. (1996) and previously used by Eydoux et al. (2000a, b). Muscle protein concentrations were determined in triplicate by the bicinchoninic acid assay (Pierce, Interchim, Montluçon, France) with bovine serum albumin as a standard and adjusted at $2 \mathrm{mg} / \mathrm{mL}$ (two samples one in each group were excluded because the protein content in muscle preparation was too low).

\section{Western blotting of MCT1, MCT4, and Glut4}

Reagents with the highest quality available were purchased from Sigma Chemicals (Saint Quentin Fallavier, France), unless otherwise stated.

Samples of muscle homogenates and prestained molecular mass markers (Bio-Rad, Ivry-sur-Seine, France) were separated on $12 \%$ sodium dodecyl sulfate (SDS)-polyacrylamide gels $(200 \mathrm{~V}$ for $\sim 60 \mathrm{~min})$ with the Novex ${ }^{\circledR}$ system (Invitrogen, Groningen, the Netherlands). Proteins were then transferred from the gels to polyvinylidenedifluoride (PVDF) membranes ( $30 \mathrm{~V}$ for $60 \mathrm{~min}$ ), and the membranes were incubated on a shaker for $1 \mathrm{~h}$ at room temperature in buffer $\mathrm{D}$ (20 mmol/L Tris base, $137 \mathrm{mmol} / \mathrm{L} \mathrm{NaCl}, 0.1 \mathrm{~mol} / \mathrm{L} \mathrm{HCl}$, adjusted to $\mathrm{pH} 7.5,0.1 \%(v / v)$ Tween 20 , and $10 \%(w / v)$ 
nonfat dried milk). The membranes were then incubated with either MCT1 antibody (1:2500, personal antibody), MCT4 antibody (1:2500, personal antibody), or Glut4 antibody (Santa Cruz sc-1608, TX, USA) in buffer D overnight followed by three washes in buffer $\mathrm{E}$ (i.e., buffer $\mathrm{D}$ without dried milk: $3 \times 5$ min washes) and then incubation for 45 min with goat anti-rabbit immunoglobulin horseradish peroxidaseconjugated secondary antibody (1:2500, BI 2407, BioSys, Compiègne, France) in buffer E. Membranes were washed as previously described, and MCT1, MCT4, or Glut4 expression was detected by enhanced chemiluminescence (ECL) (Biomax MR Films, Kodak, Montpellier, France). Films were developed and fixed using a hyperprocessor (RNP 1700, Amersham, Les Ulis, France). MCT1, MCT4, and Glut4 protein band densities were determined by scanning the blots on a scanner (AGFA Duoscan T1200, Montpellier, France) and Scion Image software (CScion Corporation, Montpellier, France). Results were expressed as in our previous studies in arbitrary unit (Py et al. 2001; Py et al. 2002).

\section{Data presentation and statistical analysis}

Data are presented as mean \pm standard error of the mean (SEM). Statistical significance of the differences between mean values was assessed by Student's $t$ test in biochemical analysis or Mann-Whitney $U$ test in Western blotting determination. The level of significance was set at $p<0.05$.

\section{Results}

\section{Effect of SMF on hematological parameter iron and transferrin levels}

SMF-exposed rats displayed significant changes in hematological parameters (Table 1). SMF-exposed rats showed a significant decrease in red blood cell (RBC) count, associated with lower $\mathrm{Hb}$ and hematocrit $(\mathrm{Ht})$ values compared to sham-exposed rats $(p<0.05)$, whereas SMF exposure did not affect white blood cells (WBC), platelet (PLT) levels, mean corpuscular values (MCV), mean corpuscular hemoglobin $(\mathrm{MCH})$, and mean corpuscular hemoglobin concentration (MCHC). SMF treatment decreased plasma iron concentration $(p<0.05)$ but increased plasma transferrin level $(p<0.05)$ (Fig. 2a, b).

\section{Effect of SMF on plasmatic glucose, insulin, and lactate levels}

SMF treatment leads, under postprandial conditions, to high level of glycemia $(205.6 \pm 5.95$ vs. $166.0 \pm 4.21 \mathrm{mg} / \mathrm{dL}$, $p<0.05)$ associated with low insulinemia compared to shamexposed rats $(1.73 \pm 0.48$ vs. $4.68 \pm 0.15 \mathrm{ng} / \mathrm{mL}, p<0.05)$.
Plasma lactate content also was strongly increased in exposed rats compared with sham-exposed rats $(3.20 \pm 0.45$ vs. $1.45 \pm$ $0.14 \mathrm{mM}, p<0.01$ ).

\section{Effect of SMF on MCT content in muscle preparation}

The investigation on MCT1 and MCT4 in the SOL (oxidative muscle) and in the EDL (glycolytic muscle) revealed that SMF exposure did not affect MCT1 content in both oxidative and glycolytic muscles. Conversely, SMF increased MCT4 only in glycolytic muscle (Figs. 3 and 4)

\section{Effect of SMF on Glut4 content in muscle preparation}

Following SMF exposure, rats displayed a high content of Glut4 in glycolytic muscle compared to sham-exposed rats, whereas in oxidative muscle quantification of Glut4 content, they did not reveal any variation (Fig. 5).

\section{Discussion}

The changes demonstrated in the present study indicate that a metabolic response was associated with hematological and iron disruption under the present exposure conditions (SMF at $128 \mathrm{mT}, 1 \mathrm{~h} /$ day/15 consecutive days).

Our proceedings revealed that SMF-exposed rats displayed a significant decrease in red blood cell (RBC) count, associated with lower $\mathrm{Hb}$ and hematocrit $(\mathrm{Ht})$ values. It was well documented that $\mathrm{Hb}$ is sensitive to SMF (Ali et al. 2003; Atef et al. 1995; Hassan and Abdelkawi 2010). This effect may be attributed to the interaction between iron heme and SMF since magnetic field penetrates the body and alters the cell membrane potential and ion distribution (Berg 1993, Kula and Drozdz 1996). Namely, application of 0.1-1 T SMF has also been reported to influence $\mathrm{Hb}$ 's conformal stability and the kinetics of the oxyhemoglobin autooxidation reaction (Atef et al. 1995). In addition, recent studies by Hassan and Abdelkawi (2010) showed that exposure to moderate and strong SMF in a range of $0.5-1.5 \mathrm{~T}$ induced change in the absorption spectra and conductivity measurements of $\mathrm{Hb}$ molecules. Furthermore, they found different degrees of globin unfolding and regarded them as a sign of molecular destabilization. This reflects the function of $\mathrm{Hb}$, which would be converted from oxyhemoglobin to nonfunctional methemoglobin with decreasing oxygen affinity. Additionally, reduction of $\mathrm{Hb}$ and $\mathrm{Ht}$ levels may be caused by an increase in plasma volume. Therefore, $\mathrm{Hb}$ concentration was below normal values in the presence of low serum iron levels (Zaghloul 2011). Cabrales et al. (2001) observed that $\mathrm{Ht}, \mathrm{Hb}$, and neutrophil levels decreased significantly after 6 months exposure $(60 \mathrm{~Hz}$, $0.11 \mathrm{mT}$ ). By contrast, Chater et al. (2006) suggested that $\mathrm{Hb}$ levels increased after 10 days exposure to SMF 
Table 1 Hematological parameters in sham-exposed and SMF-exposed rats

\begin{tabular}{llllllllll}
\hline & $\mathrm{WBC}, 10^{3} / \mathrm{mm}^{3}$ & $\mathrm{RBC}, 10^{6} / \mathrm{mm}^{3}$ & $\mathrm{Hb}, \mathrm{g} / \mathrm{dL}$ & $\mathrm{Ht}, \%$ & $\mathrm{MCV}, \mu^{3}$ & $\mathrm{MCH}, \mathrm{pg}$ & $\mathrm{MCHC}, \mathrm{g} / \mathrm{dL}$ & $\mathrm{RDW}, \%$ & $\mathrm{PLT}, 10^{3} / \mathrm{mm}^{3}$ \\
\hline Sham & $9.42 \pm 0.98$ & $8.25 \pm 0.24$ & $14.75 \pm 0.35$ & $39.95 \pm 1.01$ & $48.48 \pm 0.60$ & $17.90 \pm 0.19$ & $36.92 \pm 0.23$ & $16.20 \pm 0.15$ & $983.33 \pm 159.26$ \\
SMF & $9.73 \pm 2.38$ & $7.00 \pm 0.68^{*}$ & $12.72 \pm 0.89^{*}$ & $33.98 \pm 2.67^{*}$ & $49.13 \pm 1.65$ & $18.47 \pm 0.72$ & $37.58 \pm 0.74$ & $16.12 \pm 0.37$ & $649.33 \pm 73.43$ \\
\hline
\end{tabular}

Data represent the means \pm SEM of six animals per group

$W B C$ white blood cells, $R B C$ red blood cells, $H b$ hemoglobin, $H t$ hematocrit, $M C V$ mean corpuscular volume, $M C H$ mean corpuscular hemoglobin, $M C H C$ mean corpuscular hemoglobin concentration, $R D W$ red cell distribution width, PLT platelets

${ }^{*} p<0.05$ SMF- vs. sham-exposed rats

(128 mT). Additionally, in a previous data, we have shown that exposure during 5 days the same SMF induced increase in $\mathrm{Hb}$ and $\mathrm{Ht}$ levels (Elferchichi et al. 2007). The intensity of exposure in these two last studies $(128 \mathrm{mT})$ is similar to that used in the present data, but time of exposure is different; this difference could affect the SMF-exposed rats' hemogram response. A decrease in $\mathrm{Hb}$ and $\mathrm{Ht}$ was also observed 1 day following SMF exposure of $2 \mathrm{mT}$; however, no significant change in RBC was detected (Zaghloul 2011). In addition, SMF may cause cardiovascular stress accompanied with a slow development of mild cardiac decompensation during

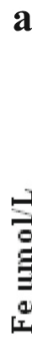

a

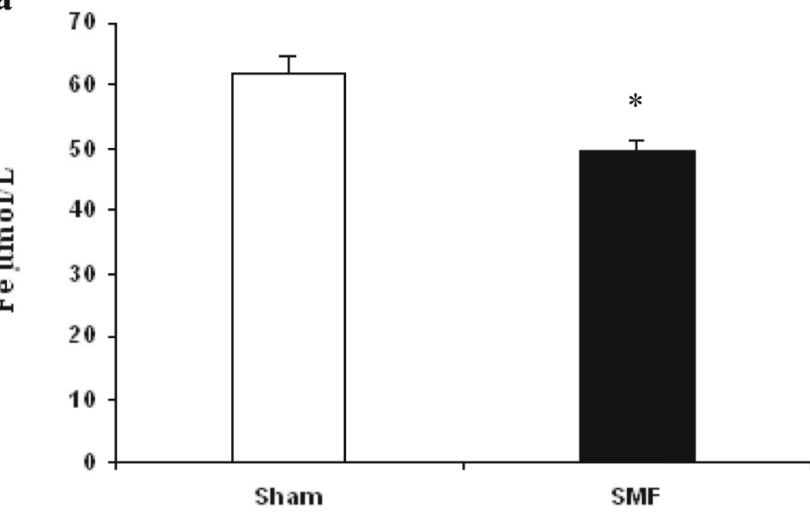

b

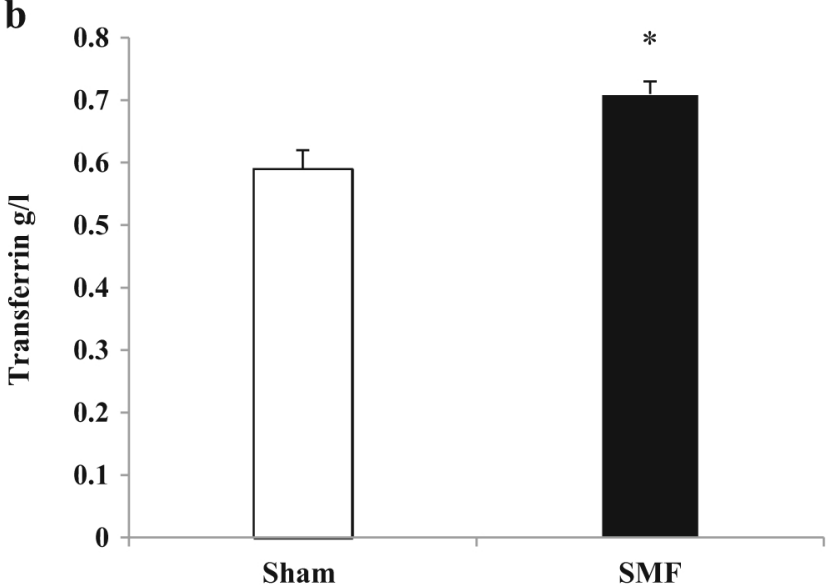

Fig. 2 Serum iron (a) and transferrin (b) concentration in sham-exposed $(n=6)$ and SMF-exposed rats $(n=6)$ rats. Values are means \pm SEM. ${ }^{*} p<0.05$, SMF vs. sham-exposed rats the exposure period (Zaghloul 2011). Thus, it can suggest that as the body adapts to the higher oxygen needs, more fluid would be in the blood. In turn, measured $\mathrm{Hb}$ and $\mathrm{Ht}$ in such cases would be low. This is because it was diluted out by a larger plasma volume, a status that reflects an anemia status. Usually, this type of anemia appears like the pseudoanemia caused by sports (Zaghloul 2011). In our proceeding, we noticed a decrease in RBC levels, and it is in accordance with the findings indicating that exposure to magnetic field $(0.2 \mathrm{mT})$ decreased RBC membrane elasticity and permeability and changed molecular structure of $\mathrm{Hb}$ (Ali et al. 2003). By contrast, mice exposed to SMF for 30 days and rats exposed to extremely low-frequency magnetic field for 50 and 100 days did not show alteration in RBC count (Cakir et al. 2009; Hashish et al. 2008). Thus, RBC fragility may lead to the increase in the $\mathrm{RBC}$ destruction rate in spleen (Osbakken et al. 1986).

On the other hand, hematological alterations may result due to iron metabolism changes. Indeed, majority of iron is located in $\mathrm{Hb}$ molecules of RBC and the rest is bound to transferrin or stored in a form of ferritin in the liver, spleen, and bone marrow (Andrews 2000). Following SMF exposure, we demonstrate a marked decrease in plasma iron level against an increase in transferrin. Our outcome is in accordance with the data reported by Zaghloul (2011), showing decrease in blood iron level 1 and 7 days following $2 \mathrm{mT} \mathrm{SMF}$ exposure. Contrariwise, after 28 days of exposure to SMF, the level of serum iron increased, and authors suggested that it is most probably a result of redistribution of metal from other compartments rich in iron such as the liver (Djordjevich et al. 2012). Recently, we have also shown that short-term exposure to SMF (128 mT/1 h/5 days) produced significant decrease in serum iron (Elferchichi et al. 2007). Because the same treatment with SMF (128 mT/1 h/5 days) induced sympathetic hyperactivity in rats (Abdelmelek et al. 2006), we postulate that decreased plasma iron level could be explained through the high turnover of norepinephrine in the noradrenergic system that could negatively influence the peristaltic activity implicated in the assimilation of divalent elements such as iron (Abdelmelek et al. 2006). Additionally, rats exposed to SMF (128 mT) exhibit higher levels of transferrin when compared to sham-exposed animals. A similar finding was observed in 
Soleus

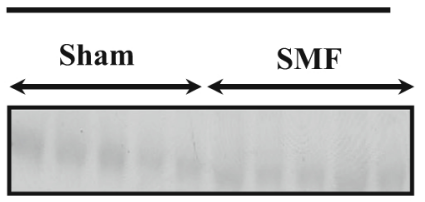

b

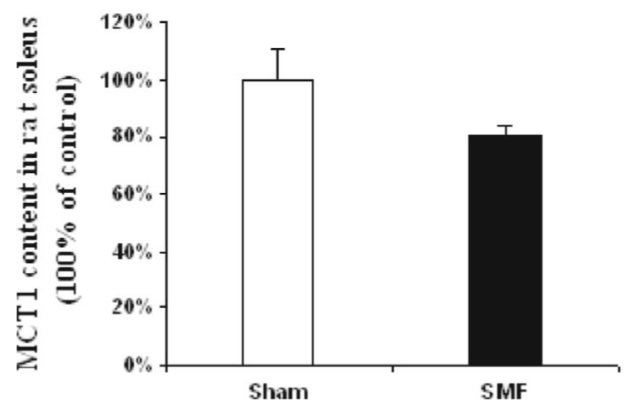

Fig. 3 Monocarboxylate transporter 1 (MCT1) expression in soleus (SOL) and extensor digitorum longus (EDL), expressed as a percentage of MCT1 in sham-exposed muscles (set to $100 \%$ in each Western blot). a Representative Western blot showing expression of MCT1 in total muscle homogenates in SOL, EDL of sham-exposed, and SMF-exposed rats. b

mice exposed to the downward oriented SMF, and it was explained as a specific adaptive reaction to subchronically induced SMF stress (Djordjevich et al. 2012).

Looking at the abovementioned results as a whole, it can be seen that SMF exposure seems to act on hematological parameters and iron homeostasis leading to a pseudoanemia status. Knowing that it is well established that iron plays a central role

a

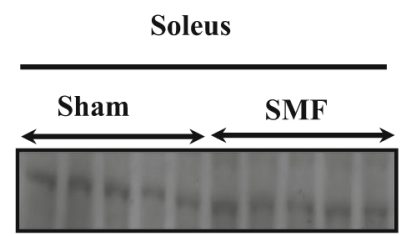

b

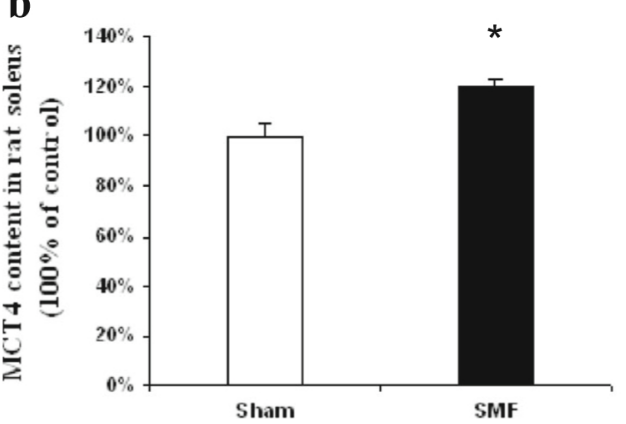

Fig. 4 Monocarboxylate transporter 4 (MCT4) expression in soleus (SOL) and extensor digitorum longus (EDL), expressed as a percentage of MCT4 in sham-exposed muscles (set to $100 \%$ in each Western blot). a Representative Western blot showing expression of MCT4 in total muscle homogenates in SOL, EDL of sham-exposed, and SMF-exposed rats. b

\section{Extensor DigitorumLongus}
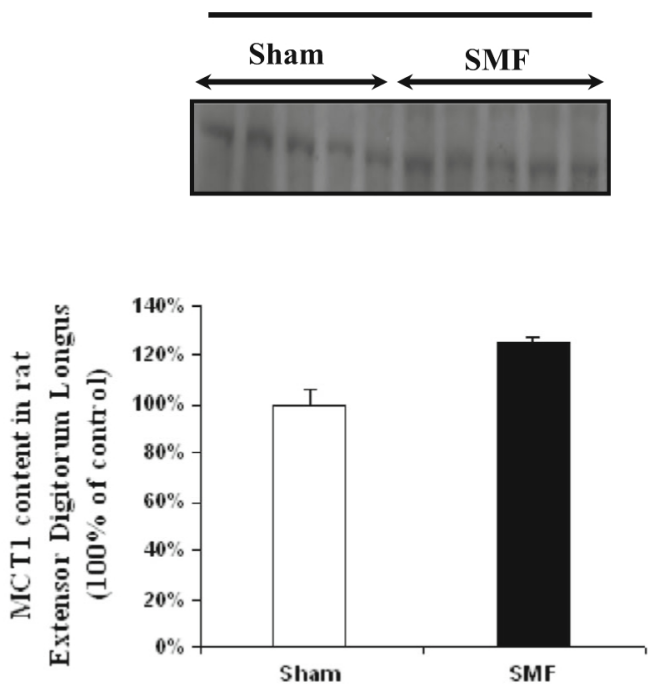

Comparison of MCT1 expression in total muscle homogenates in SOL and EDL of sham-exposed $(n=5)$ and SMF-exposed rats $(n=5)$. Values are means \pm SEM. ${ }^{*} p<0.05$ vs. sham-exposed rats. Results are expressed as a percentage of MCT1 content in sham-exposed muscle $(100 \%=$ sham-exposed MCT1 signal in each Western blot)

in the organism, it promotes the oxygenation of blood cells and muscles. So the following question arises: what will be the repercussion of the abovementioned alterations on tissue metabolism?

On systemic profile, SMF-exposed rats revealed higher blood lactate concentrations. As we pointed out in the introductory paragraphs, lactate concentration increases in many

\section{Extensor DigitorumLongus}
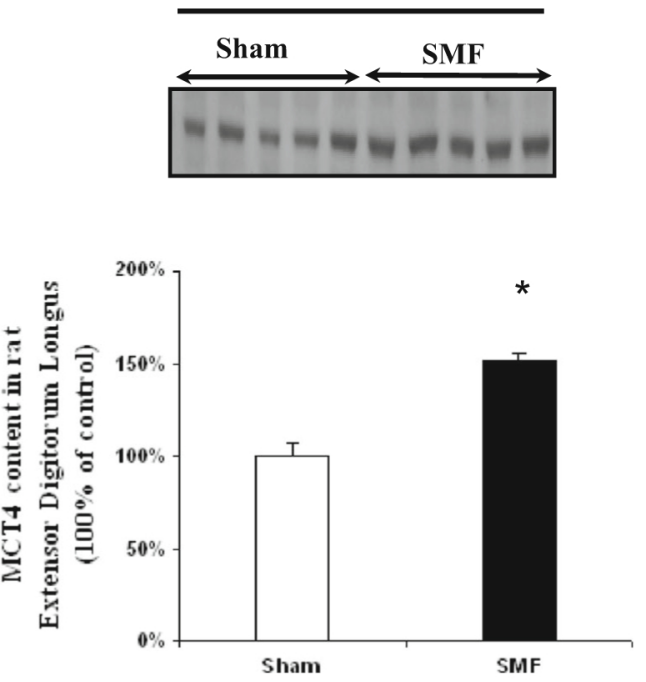

Comparison of MCT4 expression in total muscle homogenates in SOL and EDL of sham-exposed $(n=5)$ and SMF-exposed rats $(n=5)$. Values are means \pm SEM. ${ }^{*} p<0.05$ vs. sham-exposed rats. Results are expressed as a percentage of MCT4 content in sham-exposed muscle $(100 \%=$ sham-exposed MCT4 signal in each Western blot) 
$\mathbf{a}$

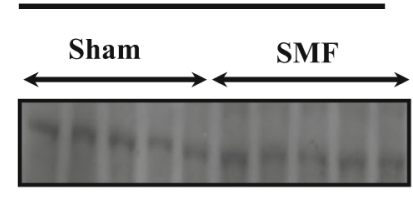

b

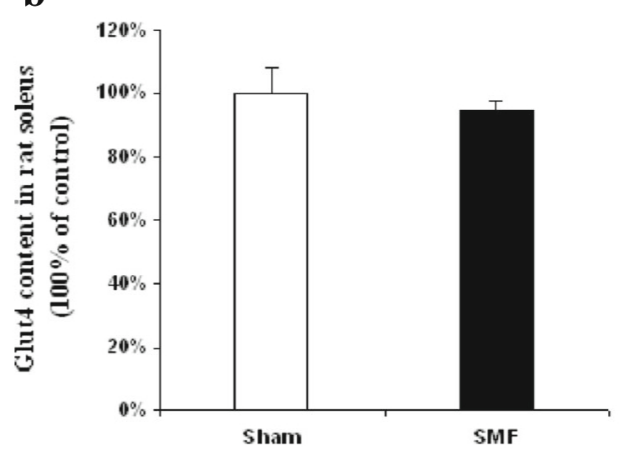

Fig. 5 Glucose transporter 4 (Glut 4) expression in soleus (SOL) and extensor digitorum longus (EDL) expressed as a percentage of Glut4 in sham-exposed muscles (set to $100 \%$ in each Western blot). a Representative Western blot showing expression of Glut4 in total muscle homogenates in SOL, EDL of sham-exposed, and SMFexposed rats. b Comparison of Glut4 expression in total muscle

physiological and pathological conditions, such as physical exercise, fasting, type 2 diabetes, obesity, and tissue hypoxia (DiGirolamo et al. 1992). In resting conditions and normal oxygenation, production of lactate is minimal within tissues functioning aerobically. By contrast, in the absence of oxygen, metabolism is oriented to anaerobic glycolysis to ensure production of small amount of energy with a concomitant synthesis of lactate (James et al. 1999). Increased plasma lactate concentration may be the result of both impaired lactate metabolism and impaired exchanges in skeletal muscle. Additionally, a hyperglycemia status associated with low insulin level was also observed following SMF treatment. On the basis of a previous published study (Elferchichi et al. 2011), we are able to suggest that SMF induced an impairment in glucose uptake and/or insulin alteration partly due to the metabolic competition between lactate and glucose tissue uptake (Miller et al. 2002; Vettor et al. 2000). So, in the presence of elevated plasma lactate, glucose uptake is reduced and lactate is used as a metabolic substrate added to the presence of low level of insulin (Lombardi et al. 1999; Vettor et al. 2000). The presence of a metabolic switch between glucose and lactate is often described in glucose homeostasis disorder such as diabetes (Elferchichi et al. 2010). These metabolic disorders are in line with an orientation toward an anaerobic lactic metabolism under SMF action with increase in lactate dehydrogenase activity and the decrease in citrate synthase activity observed only in glycolytic muscles (Elferchichi et al. 2010). It is important to consider that SMF exposure preferably
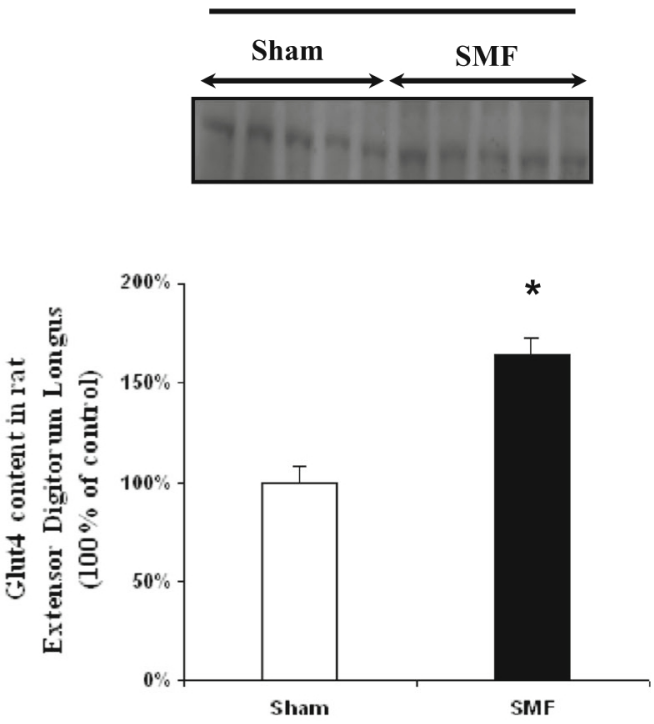

homogenates in SOL and EDL of sham-exposed $(n=5)$ and SMFexposed rats $(n=5)$. Values are mean \pm SEM. ${ }^{*} p<0.05$ vs. sham-exposed rats. Results are expressed as a percentage of Glut 4 content in shamexposed muscle $(100 \%=$ sham-exposed Glut 4 signal in each Western blot)

affects glycolytic muscles and favors lactate production through a shift from oxidative to glycolytic metabolism (Abdelmelek et al. 2006; Chater et al. 2006; Elferchichi et al. 2010). In this respect, it is tempting to implicate skeletal muscle mass in the mechanisms leading to basal hyperlactatemia (Avogaro et al. 1996). To better understand the orientation of the metabolism under SMF, we attempted to evaluate both lactate MCT isoforms (MCT1 and MCT4) and Glut4. Following SMF exposure, we clearly noticed increased MCT4 protein expression particularly in glycolytic muscle (EDL), while any effect on MCT1 content was detected in both glycolytic and oxidative muscles. From the study of McCullagh et al. (1996), it appears that MCT1 content of muscle is highly correlated with muscle lactate uptake as well as oxidative capacity. On the other hand, because MCT4 expression was found to be highly correlated with muscle glycolytic metabolism (type II fiber), it has been suggested that this transporter is required for lactate efflux (Roth and Brooks 1990). Indeed, Ullah et al. (2006) demonstrated that expression of MCT4 mRNA and protein was increased threefold by $48 \mathrm{~h}$ exposure to $1 \% \mathrm{O}_{2}$ while MCT1 expression was not increased. These authors concluded that MCT4, like other glycolytic enzymes, is upregulated by hypoxia mechanism. This adaptive response allows the increased lactic acid produced during hypoxia to be rapidly lost from the cell.

Additionally, only EDL muscle displayed a significant increase in Glut4 content. It is well documented that insulin stimulates glucose uptake by promoting the translocation of 
the Glut4 isoform from cytoplasm to the plasma membrane (Sano et al. 2011; Vijayakumar and Bhat 2012). However, under SMF action, and in the presence of low insulin level, the increase in Glut4 content in EDL muscle could be explained by stimulation of synthesis of the transporter in presence of low-energy production.

\section{Conclusions}

The present study shows that SMF exposure seems to provide a pseudoanemia status, reducing the oxygen tissue delivery, which will likely result in tissue hypoxia. Thus, adaptation to anaerobic conditions is extrapolated to glucose and lactate transporters that react differently to the hypoxia status. Nevertheless, our results should be confirmed by further investigation. Extrapolation of these results to humans is not straightforward and any such comparison should be made with great caution. Although this does not preclude the fact that the exposure limits should be revised.

Acknowledgments This work has been supported by PHYMEDEXP, INSERM U1046, CNRS UMR 9214, Université de Montpellier.

Conflict of interest The authors declare that they have no competing interests.

\section{References}

Abdelmelek H, Molnar A, Servais S, Cottet-Emard JM, Pequignot JM, Favier R, Sakly M (2006) Skeletal muscle HSP72 and norepinephrine response to static magnetic field in rat. J Neural Transm 113(7): 821-827

Ali FM, Mohamed WS, Mohamed MR (2003) Effect of $50 \mathrm{~Hz}, 0.2 \mathrm{mT}$ magnetic field on RBC properties and heart functions of albino rats. Bioelectromagnetics 24(8):535-545

Andrews NC (2000) Iron metabolism: iron deficiency and iron overload. Annu Rev Genomics Hum Genet 1(75-98):1527-8204

Atef MM, MS A e-B, el-Kareem A, Aida S, Fadel MA (1995) Effects of a static magnetic field on haemoglobin structure and function. Int $\mathrm{J}$ Biol Macromol 17(2):105-111

Avogaro A, Toffolo G, Miola M, Valerio A, Tiengo A, Cobelli C, Del Prato S (1996) Intracellular lactate- and pyruvate-interconversion rates are increased in muscle tissue of non-insulindependent diabetic individuals. J Clin Invest 98(1):108-115

Berg H (1993) Electrostimulation of cell metabolism by low frequency electric and electromagnetic fields. Bioelectrochem Bioenerg 31(1): $1-25$

Binhi VN (2002) Magnetobiology: underlying physical problems. Academic, San Diego

Cabrales LB, Ciria HC, Bruzón RP, Quevedo MS, Céspedes MC, Salas MF (2001) ELF magnetic field effects on some hematological and biochemical parameters of peripheral blood in mice. Electromagn Biol Med 20(2):185-191

Cakir DU, Yokus B, Akdag MZ, Sert C, Mete N (2009) Alterations of hematological variations in rats exposed to extremely low frequency magnetic fields (50 Hz). Arch Med Res 40(5):352-356
Chater S, Abdelmelek H, Pequignot JM, Sakly M, Rhouma KB (2006) Effects of sub-acute exposure to static magnetic field on hematologic and biochemical parameters in pregnant rats. Electromagn Biol Med 25(3):35-144

DiGirolamo M, Newby FD, Lovejoy J (1992) Lactate production in adipose tissue: a regulated function with extra-adipose implications. FASEB J 6(7):2405-2412

Djordjevich DM, De Luka SR, Milovanovich ID, Jankovic S, Stefanovic S, Veskovic-Moracanin S, Cirkovic S, Ilic AZ, Ristic-Djurovic JL, Trbovich AM (2012) Hematological parameters' changes in mice subchronically exposed to static magnetic fields of different orientations. Ecotoxicol Environ Safety 81(1):98-105

Elferchichi M, Abdelmelek H, Sakly M (2007) Effects of sub-acute exposure to static magnetic field on iron status and hematopoiesis in rats. Turk J Haematol 24(2):64-68

Elferchichi M, Mercier J, Coisy-Quivy M, Metz L, Lajoix AD, Gross R, Belguith H, Abdelmelek H, Sakly M, Lambert K (2010) Effects of exposure to a $128-\mathrm{mT}$ static magnetic field on glucose and lipid metabolism in serum and skeletal muscle of rats. Arch Med Res 41(5):30914

Elferchichi M, Mercier J, Bourret A, Gross R, Lajoix AD, Belguith $\mathrm{H}$, Abdelmelek H, Sakly M, Lambert K (2011) Is static magnetic field exposure a new model of metabolic alteration? Comparison with Zucker rats. Int J Radiat Biol 87(5):48390

Eydoux N, Dubouchaud H, Py G, Granier P, Prefaut C, Mercier J (2000a) Lactate transport in rat sarcolemmal vesicles after a single bout of submaximal exercise. Int J Sports Med 21(6): 393-9

Eydoux N, Py G, Lambert K, Dubouchaud H, Prefaut C, Mercier J (2000b) Training does not protect against exhaustive exerciseinduced lactate transport capacity alterations. AJP Endocrinology and Metabolism. 278 (6): 1045-52

Feychting M (2005) Health effects of static magnetic fields: a review of the epidemiological evidence. Prog Biophys Mol Biol 87(2-3):241246

Gutmann I, Wahlefeld M (1974) L (p) lactate determination with lactate dehydrogenase and NAD. Methods of enzymatic analysis. Academic, New York, pp 1464-1472

Hashish AH, El-Missiry MA, Abdelkader HI, Abou-Saleh RH (2008) Assessment of biological changes of continuous whole body exposure to static magnetic field and extremely low frequency electromagnetic fields in mice. Ecotoxicol Environ Safety 71(3):895-902

Hassan NS, Abdelkawi SA (2010) Changes in molecular structure of hemoglobin in exposure to $50 \mathrm{~Hz}$ magnetic fields. Nature 8(8): 236-243

Havas M (2008) Dirty electricity elevates blood sugar among electrically sensitive diabetics and may explain brittle diabetes. Electromagn Biol Med 27(2):135-146

James JH, Luchette FA, McCarter FD, Fischer JE (1999) Lactate is an unreliable indicator of tissue hypoxia in injury or sepsis. Lancet 354(9177):505-508

Juel C, Halestrap AP (1999) Lactate transport in skeletal muscle: role and regulation of the monocarboxylate transporter. J Physiol 517(3): 633-642

Kowalczuk CI, Sienkiewiczk ZJ, Saunders RD (1991) Biological effects of exposure to non-ionizing electromagnetic fields and radiation I. Static electric and magnetic fields. National Radiological Protection Board, NRPB-R238, Didcot, UK

Kula B, Drozdz M (1996) A study of magnetic field effects on fibroblasts cultures, part 2: The evaluation of effects of static and extremely low frequency (ELF) magnetic fields on free radical processes in fibroblasts cultures. Bioeletrochem Bioenerg 39(1):27-30

Lombardi AM, Fabris R, Bassetto F, Serra R, Leturque A, Federspil G, Girard J, Vettor R (1999) Hyperlactatemia reduces muscle glucose uptake and GLUT-4 mRNA while increasing (E1alpha) PDH gene expression in rat. AJP 276(5 Pt 1):922-929 
McCullagh KJ, Poole RC, Halestrap AP, O'Brien M, Bonen A (1996) Role of the lactate transporter (MCT1) in skeletal muscles. AJP 271(1):143-150

McRobbie DW (2012) Occupational exposure in MRI. Br J Radiol 85(1012):293-312

Miller BF, Fattor JA, Jacobs KA, Horning MA, Navazio F, Lindinger MI, Brooks GA (2002) Lactate and glucose interactions during rest and exercise in men: Effect of exogenous lactate infusion. J Physiol 544(3):963-975

Osbakken M, Griffith J, Taczanowsky PA (1986) Gross morphologic, histologic, hematologic, and blood chemistry study of adult and neonatal mice chronically exposed to high magnetic fields. Magn Reson Med 3(4):502-517

Py G, Lambert K, Perez-Martin A, Raynaud E, Prefaut C, Mercier J (2001) Impaired sarcolemmal vesicle lactate uptake and skeletal muscle MCT1 and MCT4 expression in obese Zucker rats. AJP Endocrinology and Metabolism 281(6):1308-1315

Py G, Lambert K, Milhavet O, Eydoux N, Prefaut C, Mercier J (2002) Effects of streptozotocin-induced diabetes on markers of skeletal muscle metabolism and monocarboxylate transporter 1 to monocarboxylate transporter 4 transporters. Metabolism 51(7):807-813

Repacholi MH, Greenebaum B (1999) Interaction of static and extremely low frequency electric and magnetic fields with living systems: health effects and research needs. Bioelectromagnetics 20(3):133160
Roth DA, Brooks GA (1990) Lactate transport is mediated by a membrane-bound carrier in rat skeletal muscle sarcolemmal vesicles. Arch Biochem Biophys 279(2):377-385

Sano H, Peck GR, Kettenbach AN, Gerber SA, Lienhard GE (2011) Insulin-stimulated GLUT4 protein translocation in adipocytes requires the Rab10 guanine nucleotide exchange factor Dennd4C. J Biol Chem 286(19): 165-415

Saunders R (2005) Static magnetic fields: animal studies. Prog Biophys Mol Biol 87(2-3):225-239

Schenck JF (2000) Safety of strong, static magnetic fields. J Magn Reson Imaging 12(1):2-19

Ullah MS, Davies AJ, Halestrap AP (2006) The plasma membrane lactate transporter MCT4, but not MCT1, is up-regulated by hypoxia through a HIF-1alpha-dependent mechanism. J Biol Chem 281(14):9030-9903

Vettor R, Lombardi AM, Fabris R, Serra R, Pagano C, Macor C, Federspil $\mathrm{G}$ (2000) Substrate competition and insulin action in animal models. Int J Obes Relat Metab Disord 24(2):22-24

Vijayakumar MV, Bhat MK (2012) Real time qualitative and quantitative GLUT4 translocation assay. Methods Enzymol 505(14):257-271

World Health Organisation (2006) Static fields, Environmental Health Criteria. World Health Organization 20(1):349, http://www.who. int/pehemf/publications/EHC_232

Zaghloul MS (2011) Effects of chronic exposure to static electromagnetic field on certain histological aspects of the spleen and some haematological parameters in Albino Rats. Am J Sci 7(8):383-394 